\title{
Dynamic hydraulic models to study sedimentation in drinking water networks in detail
}

\author{
I. W. M. Pothof ${ }^{1,2}$ and E. J. M. Blokker ${ }^{3}$ \\ ${ }^{1}$ Deltares/Industrial Hydrodynamics, Delft, The Netherlands \\ ${ }^{2}$ Delft University of Technology/Water management, Delft, The Netherlands \\ ${ }^{3}$ KWR Watercycle Research Institute, Nieuwegein, The Netherlands
}

Correspondence to: I. W. M. Pothof (ivo.pothof@ deltares.nl)

Received: 23 February 2012 - Published in Drink. Water Eng. Sci. Discuss.: 4 April 2012

Revised: 13 November 2012 - Accepted: 3 December 2012 - Published: 14 December 2012

\begin{abstract}
Sedimentation in drinking water networks can lead to discolouration complaints. A sufficient criterion to prevent sedimentation in the Dutch drinking water networks is a daily maximum velocity of $0.25 \mathrm{~m} \mathrm{~s}^{-1}$. Flushing experiments have shown that this criterion is a sufficient condition for a clean network, but not a necessary condition. Drinking water networks include many locations with a maximum velocity well below $0.25 \mathrm{~m} \mathrm{~s}^{-1}$ without accumulated sediments. Other criteria need to be developed to predict which locations are susceptible to sedimentation and to prevent sedimentation in future networks. More distinctive criteria are helpful to prioritise flushing operations and to prevent water quality complaints.
\end{abstract}

The authors use three different numerical modelling approaches - quasi-steady, rigid column and water hammer - with a temporal discretisation of $1 \mathrm{~s}$ in order to assess the influence of unsteady flows on the wall shear stress, causing resuspension of sediment particles. The model predictions are combined with results from flushing experiments in the drinking water distribution system of Purmerend, the Netherlands. The waterhammer model does not result in essentially different flow distribution patterns, compared to the rigid column and quasi-steady modelling approach. The extra information from the waterhammer model is a velocity oscillation of approximately $0.02 \mathrm{~m} \mathrm{~s}^{-1}$ around the quasi-steady solution. The presence of stagnation zones and multiple flow direction reversals seem to be interesting new parameters to predict sediment accumulation, which are consistent with the observed turbidity data and theoretical considerations on critical shear stresses.

\section{Introduction}

The goal of drinking water companies is to supply their customers with good quality drinking water $24 \mathrm{~h}$ per day. With respect to water quality, the focus has for many years been on the drinking water treatment. Recently, interest in water quality in the drinking water distribution system (DWDS) has been growing. On the one hand, this is driven by customers who expect the water company to ensure the best water quality by preventing such obvious deficiencies in water quality as discolouration and (in many countries) by assuring a sufficient level of chlorine residual. On the other hand, since "9/11" there is a growing concern about (deliberate) contaminations in the DWDS.
Sedimentation in drinking water networks may lead to discolouration complaints. A sufficient criterion for Dutch DWDS, consisting of PVC, AC and lined CI mains, to prevent sedimentation is a daily maximum velocity of $0.25 \mathrm{~m} \mathrm{~s}^{-1}$ (Blokker et al., 2010a). Flushing experiments have shown that this criterion is a sufficient condition for a clean network, but not a necessary condition.

Transient models, including pressure wave propagation, are used for waterhammer analysis and for the evaluation of valve operations, pump switches and the design of control systems. More recently, transient models have been applied in DWDS for the prediction of a number of water quality parameters, such as chlorine decay or intrusion volumes during low pressure transients (Ebacher et al., 2011). 


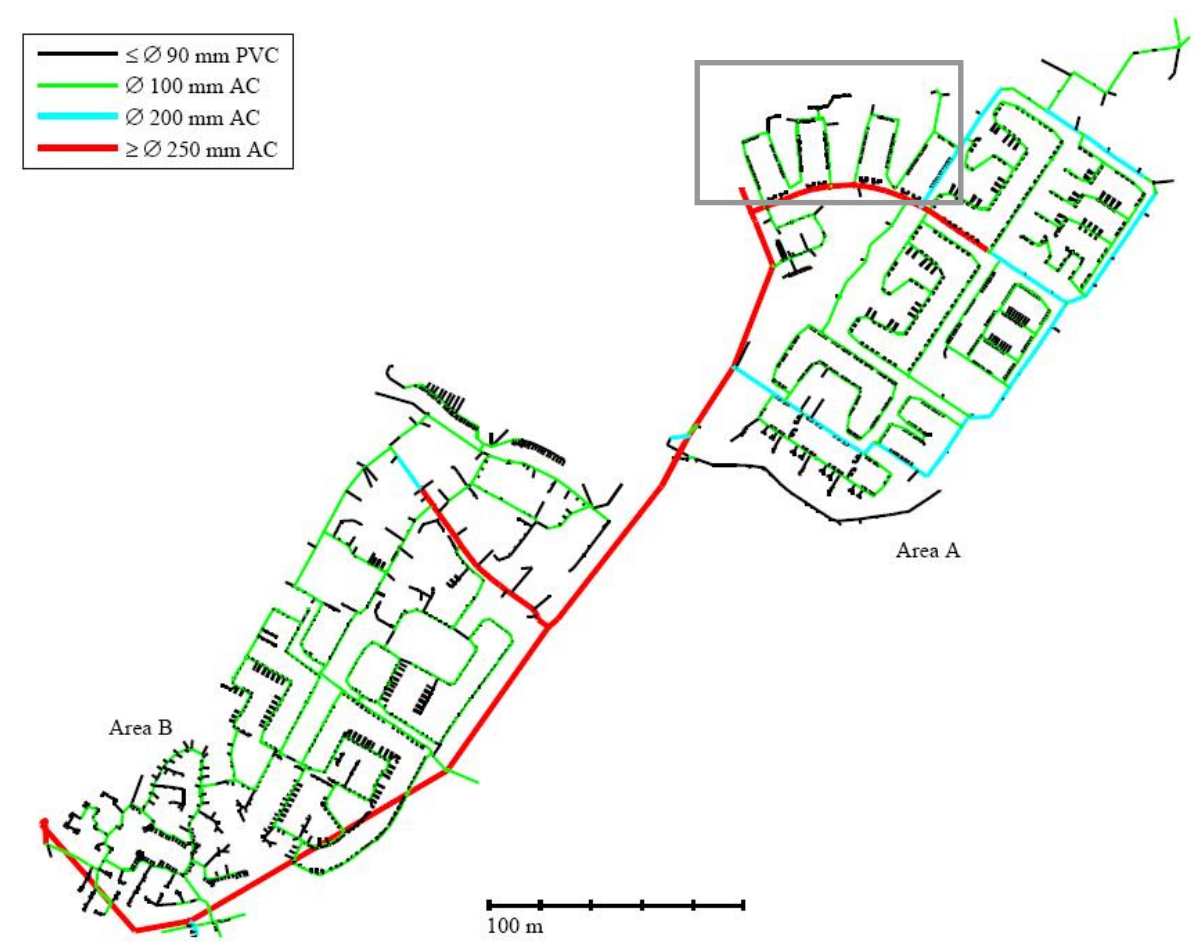

Figure 1. Purmerend DWDS and selected test area (grey rectangle). Source: Blokker et al. (2010a).

In this paper, we investigate whether more detailed hydrodynamic models will result in more accurate criteria for the prediction, efficient mitigation and ultimately prevention of sedimentation in the DWDS. We have used three different numerical modelling approaches: (1) the traditional quasisteady model, as implemented in EPANET-based models; (2) a rigid column model, in which the inertia of the water mass in all pipes is taken into account and (3) the complete waterhammer model, including liquid compressibility and pipe stiffness so that the propagation of pressure waves is correctly simulated (Wylie and Streeter, 1993). The quasisteady modeling results were obtained with EPANET (Rossman, 2000). The Rigid Column (RC) and waterhammer results were obtained with WANDA, developed and validated by Deltares (Deltares, 1993-2011).

\section{Approach}

\subsection{Network selection}

Ideally, we would investigate a DWDS with loops and a single water source in which sedimentation has been measured in all pipes and in which the velocity time series between two consecutive flushing procedures has been measured in all pipes. Turbidity measurements during well-defined flushing procedures provide a reasonable spatial distribution of the sediment load in all flushed pipes. Obviously, the second criterion is not practically feasible in any DWDS. However, if the network layout (pipe length, material, internal diameter, wall roughness) is known and sufficient demographic information is available on the inhabitants, then a reasonable assessment of the time series of the velocities can be computed from detailed stochastic water demand model simulations with SIMDEUM (Blokker et al., 2010b).

The turbidity was measured during flushing procedures in the Purmerend DWDS (the Netherlands). Furthermore, a SIMDEUM model of the Purmered DWDS is available. The Purmerend DWDS and the flushing procedure are described by Blokker (2010) and in two papers, presented at the 2011 CCWI conference (Blokker et al., 2011; Schaap and Blokker, 2011). An area within the Purmerend DWDS has been selected based on the availability of accurate sedimentation data obtained via flushing procedures. Furthermore, the test area includes sections with a lot of accumulated sediment and other similar sections without. The test area is shown in Fig. 1 . The test area includes approximately 200 house connections and 450 pipes. The water demands of the individual households are a realization of the stochastic water demand model SIMDEUM (Blokker, 2010). The water demands have a temporal resolution of $1 \mathrm{~s}$. The simulations cover a period from 05:00 a.m. until 11:00 a.m., so that the minimum and maximum water demands are included. 
Table 1. Pipe properties for waterhammer model for pipes with a pressure rating of 6 barg.

\begin{tabular}{llll}
\hline $\begin{array}{l}\text { Pipe } \\
\text { material }\end{array}$ & $\begin{array}{l}\text { Young's } \\
\text { modulus } \\
{[\mathrm{Gpa}]}\end{array}$ & $\begin{array}{l}\text { Internal } \\
\text { diameter } \\
{[\mathrm{mm}]}\end{array}$ & $\begin{array}{l}\text { Wall } \\
\text { thickness } \\
{[\mathrm{mm}]}\end{array}$ \\
\hline & & 19.6 & 1.2 \\
& & 25 & 1.2 \\
PVC & 3 & 44.2 & 2.0 \\
& & 59 & 2.0 \\
& & 90 & 2.7 \\
\hline & & 100 & 10 \\
AC & 30 & 150 & 10 \\
& & 200 & 11 \\
& & 400 & 12 \\
\hline
\end{tabular}

\subsection{Rigid column and waterhammer model}

The Rigid column model does not need any additional information in comparison with the EPANET model. The only difference is the extension of the momentum equation with the inertia term:

$\Delta H=\frac{\lambda L}{D} \frac{v^{2}}{2 g}+\frac{L}{g} \frac{\mathrm{d} v}{\mathrm{~d} t}$

where $\Delta H[\mathrm{~m}]$ is the differential head of an individual pipe in the DWDS, $\lambda[-]$ is the quasi-steady friction factor according to White-Colebrook, $L$ the pipe length, $D[\mathrm{~m}]$ is the internal pipe diameter, $v\left[\mathrm{~m} \mathrm{~s}^{-1}\right]$ is the pipe velocity and $g\left[\mathrm{~m} \mathrm{~s}^{-2}\right]$ is the constant of gravitational acceleration.

The more advanced waterhammer model takes the pipe elasticity and water compressibility into account, so that the effects of pressure waves in the network are computed. This requires additional information on the pipe material and wall thickness. The pipe materials are shown in Fig. 1 and the applied wall thickness values and Young's moduli are listed in Table 1.

These data result in typical acoustic wave speeds of $350 \mathrm{~m} \mathrm{~s}^{-1}$ in PVC pipes and $1000 \mathrm{~m} \mathrm{~s}^{-1}$ in AC pipes. Pipes with a length of less than $2 \mathrm{~m}$ have been modelled as rigid column pipes, in order to prevent a time step of less than $0.002 \mathrm{~s}$. The timestep of the waterhammer model is $0.003 \mathrm{~s}$.

Due to the fact that the test area includes two loops, the rigid column and waterhammer models may lead to a different pressure and flow distribution than the EPANET model, due to the presence of the inertia term in the momentum balance. Both modelling approaches have been modeled in WANDA (Deltares, 1993-2011). All boundary conditions are identical for the three different modeling approaches.

\subsection{Sedimentation and resuspension}

The typical particle size $(d<25 \mu \mathrm{m}=0.025 \mathrm{~mm})$ (Vreeburg, $2007)$ and particle density $\left(\rho_{\mathrm{s}}=1200 \mathrm{~kg} \mathrm{~m}^{-3}\right)$ of material in

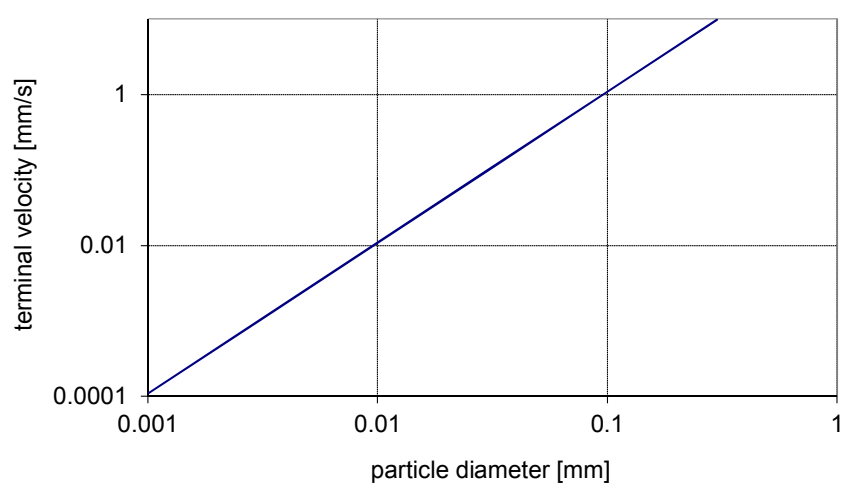

Figure 2. Particle terminal falling velocity as a function of particle size; $\rho_{\mathrm{s}}=1200 \mathrm{~kg} \mathrm{~m}^{-3}$.

drinking water networks are so small that the terminal velocity can be determined with Stokes' law. The terminal particle velocity $v_{\mathrm{t}}\left[\mathrm{m} \mathrm{s}^{-1}\right]$ follows directly from:

$v_{\mathrm{t}}=\frac{\left(\rho_{\mathrm{s}}-\rho_{\mathrm{f}}\right)}{\mu_{\mathrm{f}}} \frac{g d^{2}}{18}$

The terminal velocity $v_{\mathrm{t}}$ is only $0.07 \mathrm{~mm} \mathrm{~s}^{-1}$ at particle diameter $d=0.025 \mathrm{~mm}$ and $\rho_{\mathrm{s}}=1200 \mathrm{~kg} \mathrm{~m}^{-3}$ and fluid density $\rho_{\mathrm{f}}=1000 \mathrm{~kg} \mathrm{~m}^{-3}$ (Fig. 2); $\mu_{\mathrm{f}}[\mathrm{Pa} \mathrm{s}]$ is the dynamic viscosity of water. A particle of this size needs $12 \mathrm{~min}$ to drop $50 \mathrm{~mm}$. If these particles do settle at all, they will easily be resuspended at the so-called critical shear stress. Settled particles reside in the laminar sublayer of a distribution pipe. Therefore, Soulsby's model for the critical shear stress is applied (Soulsby, 1997). Soulsby has developed his model for noncohesive particles. For particles smaller than $100 \mu \mathrm{m}$ the dimensionless critical shear stress $\theta_{\text {cr }}$ tends to 0.3 , but experimental evidence is limited in this particle range. The shear stress $\tau_{\text {cr }}[\mathrm{Pa}]$ then becomes:

$\tau_{\mathrm{cr}}=\theta_{\mathrm{cr}}\left(\rho_{\mathrm{s}}-\rho_{\mathrm{f}}\right) g d=0.015 \mathrm{~Pa}$

where a maximum particle size of $d=0.025 \times 10^{-3} \mathrm{~m}$ was substituted. The critical shear stress may increase if the particles exhibit cohesive behaviour.

The laminar wall shear stress $\tau_{\mathrm{w}, \text { lam }}[\mathrm{Pa}]$ is a known function of the average pipe velocity $U\left[\mathrm{~m} \mathrm{~s}^{-1}\right]$ and pipe radius $R$ [m].

$\tau_{\mathrm{w}, \operatorname{lam}}=\frac{R}{2} \frac{\mathrm{d} p}{\mathrm{~d} x}=\frac{4 \mu_{\mathrm{f}} U}{R}$

If the flow becomes turbulent $(R e>2300)$, then a typical friction factor is $\lambda=0.03$ for pipes with diameter $D=0.1 \mathrm{~m}$. In this case the wall shear stress $\tau_{\mathrm{w}, \text { tur }}[\mathrm{Pa}]$ is computed as

$\tau_{\mathrm{w}, \text { tur }}=\frac{\lambda}{8} \rho_{\mathrm{f}} U^{2}=3.75 U^{2}$

The critical shear stress for resuspension and the steady wall shear stress in a pipe with $D=0.1 \mathrm{~m}$ have been 


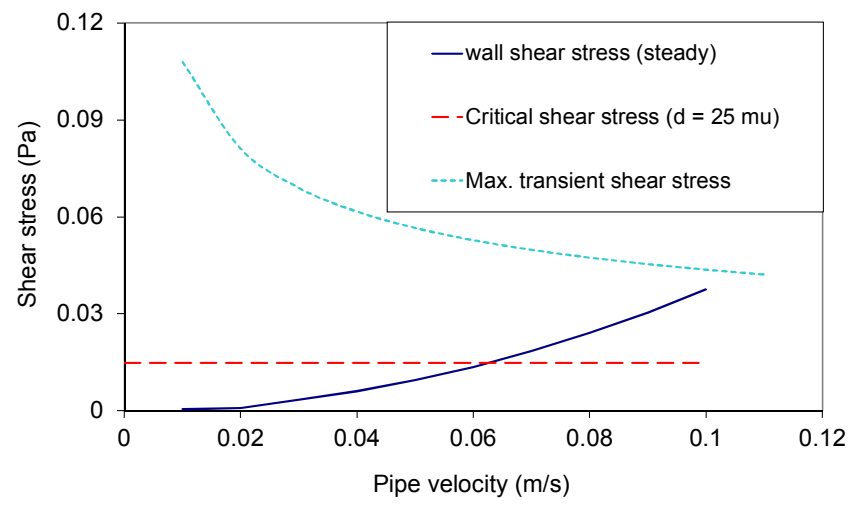

Figure 3. Wall shear stress (Eqs. 4 and 5), critical shear stress for resuspension (Eq. 3) and maximum unsteady shear stress (Eq. 6).

plotted in Fig. 3, showing that the larger particles $\left(\rho_{\mathrm{s}}=\right.$ $1200 \mathrm{~kg} \mathrm{~m}^{-3}$ and $d=25 \mu \mathrm{m}$ ) will move if the water velocity $U>0.06 \mathrm{~m} \mathrm{~s}^{-1}$. The critical shear stress for resuspension increases linearly with the particle diameter and density, so that the critical water velocity for other particles can be derived from Fig. 3.

Due to acceleration and deceleration of the flow, the velocity profile does not vary in a quasi-steady manner. Therefore, the unsteady wall shear stress may contribute significantly to the total wall shear stress. The modelling of these unsteady friction phenomena has not yet led to a generally accepted modelling approach. Brunone et al. (2000) has proposed a model that is based on instantaneous accelerations. Others have extended unsteady friction models for laminar flows (Vardy and Brown, 2003), based on Zielke (1968). Pothof (2008) has developed a model in which the unsteady shear stress model is based on a decelerating turbulent flow. Vardy and Brown (2003) have derived a maximum unsteady wall shear stress, $\tau_{\mathrm{wu}, \max }[\mathrm{Pa}]$ :

$\tau_{\mathrm{wu}, \max }=\frac{\rho_{\mathrm{w}} \sqrt{C^{*}} D \mathrm{~d} U / \mathrm{d} t}{2}$

where $C^{*}[-]$ is a function of the Reynolds number

$C^{*}=12.86 / R e^{\kappa}$

$\kappa=\log \left(15.29 / R e^{0.0567}\right)$

The transient simulation with the waterhammer model shows typical velocity decelerations of $2 \mathrm{~cm} \mathrm{~s}^{-2}$, independent of the water velocity. This information can be combined with Eq. (6) to obtain the maximum unsteady shear stress in a pipe with $D=0.1 \mathrm{~m}$ as a function of the water velocity (Fig. 3). Figure 3 shows that particles of $d=25 \mu \mathrm{m}$ may be easily resuspended by flow acceleration or decelerations at velocities well below $U=0.06 \mathrm{~m} \mathrm{~s}^{-1}$.

This analysis suggests that sedimentation can only occur in stagnation zones. We will therefore focus on the stagnation zones in the network loops.

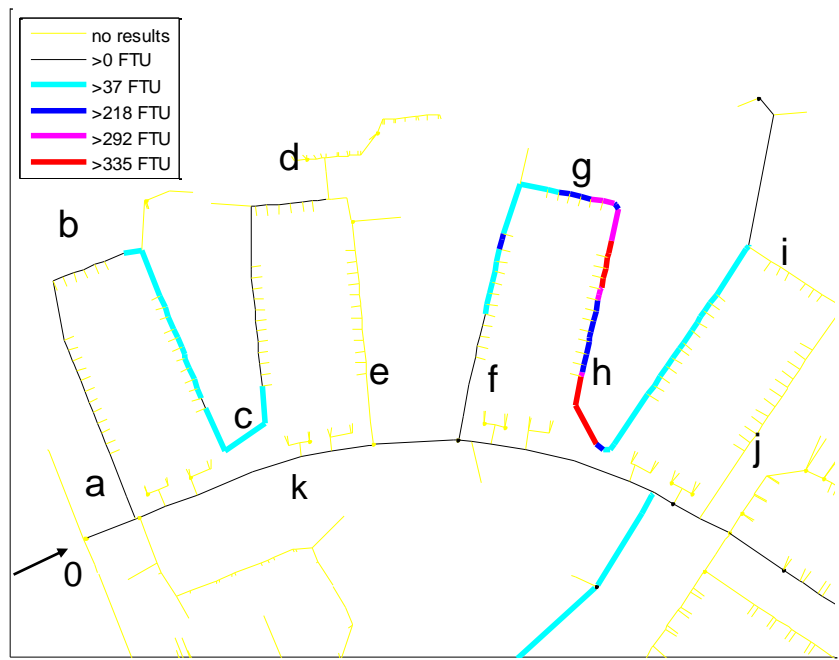

Figure 4. Spatial distribution of turbidity measurement in the Purmerend test area.

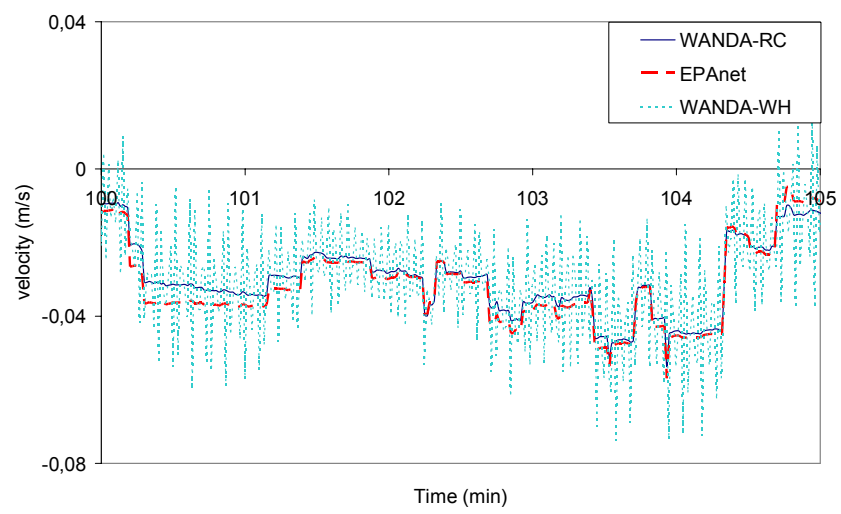

Figure 5. 5-min detail of the three modelling approaches in pipe e $(100=06: 40$ a.m. $)$.

\section{Results}

\subsection{Turbidity measurements}

The turbidity time series measurements have been translated to a spatial distribution of turbidity (Fig. 4). For each flushing action, the measured turbidity [FTU, Formazin Turbidity Unit] of the 1st turnover was linked to the location in the stretch of pipes from which the particles originated. This was done by converting the measurement time [s] to the flushed pipe length $[\mathrm{m}]$ with the help of the flushing flow $\left[\mathrm{m}^{3} \mathrm{~s}^{-1}\right]$ and pipe diameter [m] (Blokker et al., 2010a). For some pipe stretches no results are shown in Fig. 4, because the pipe was not flushed, or the conversion to the pipe length was too inaccurate in case of short flushing times, leaking valves or high turbidities in the 2nd turnover.

Both loops in the test area (a-b-c-d-e and f-g-h-i-j) are very similar with respect to pipe diameter and spatial distribution 

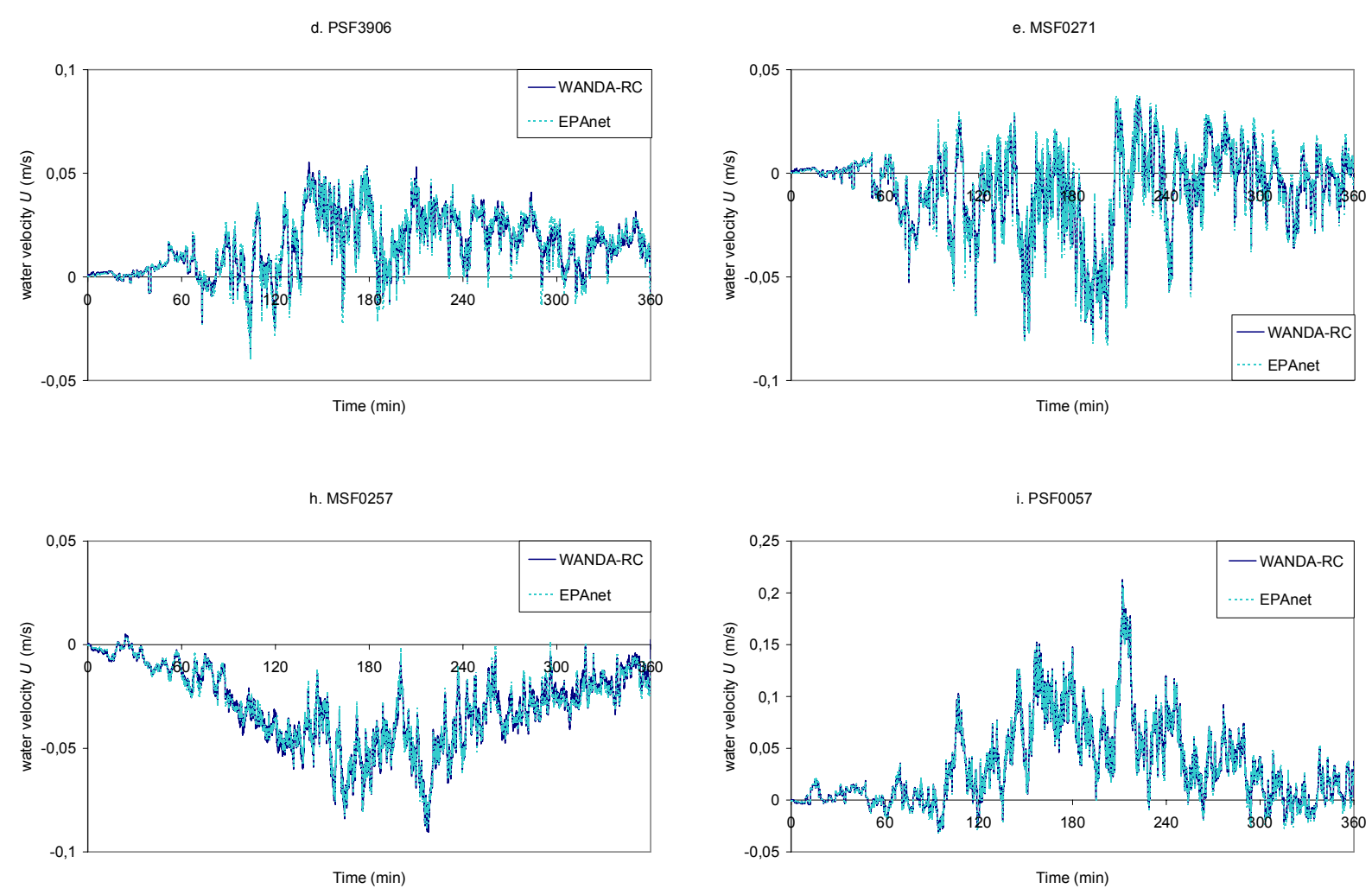

Figure 6. Velocities in reaches d, e., h and i (labels in Fig. 4); start time corresponds to 05:00 a.m.

of homes. However, the first loop hardly contains any sediment, whereas a fair amount of sediment was found in the second loop. Following the reasoning in Sect. 2, a stagnation zone should be absent in loop (b-c-d) and present in loop (g$\mathrm{h}-\mathrm{i})$. The presence of stagnation zones will be discussed in Sect. 3.2.

\subsection{Simulation results}

The rigid column model is practically identical to the EPANET model, even at the temporal resolution in demands of $1 \mathrm{~s}$, as illustrated in Figs. 5 and 6. The waterhammer model shows typical velocity oscillations of $0.02 \mathrm{~m} \mathrm{~s}^{-1}$ and typical accelerations of $0.02 \mathrm{~m} \mathrm{~s}^{-2}$ around the EPANET solution (Fig. 5). Since the magnitude of velocity oscillations are independent of the absolute velocities, these simulations suggest that these oscillations are generally valid at the local network level, but this statement requires further substantiation with local measured flow data at the appropriate temporal scale of $1 \mathrm{~s}$ as applied in these simulations. These kind of flow data were not available for the Purmerend test area.

The stochastic nature of the drinking water demand is responsible for spatial variation of the stagnation point. In fact, there is no stagnation zone, but there are pipes where many flow reversals occur. The velocity time series at location e contains most flow reversals; this is the connection with the large AC pipe, marked k in Fig. 4. The simulated flow is uni-directional most of the time between pipes a and d, so that stagnation does not occur in these pipes. Since sediment was hardly measured between pipes a. and d., the presence of stagnation zones or the number of flow direction reversals may correlate with the sediment load. In the second loop (f$\mathrm{g}-\mathrm{h}-\mathrm{i}-\mathrm{j}$ ) the stagnant zone is located between pipes $\mathrm{h}$. and $\mathrm{i}$. (Fig. 6) and most sediment was measured near pipe h. and between pipes $g$. and $h$. The presence of a stagnant zone, or equivalently many flow direction reversals, in the loop (f-g$\mathrm{h}-\mathrm{i}-\mathrm{j}$ ) may be an indication for the presence of sediment. The match between the sediment concentration and the number of flow direction reversals is not perfect, because of a number of inherent uncertainties associated with DWDS modelling and the turbidity data processing. First, the actual water demand distribution over the years may differ somewhat from the simulated demand distribution of only one day. More simulations can show the variability of the flow distributions and the location of the stagnation zones. Secondly, the turbidity data analysis assumes that the sediment bed erodes completely and instantaneously during the flushing procedure. In reality, the bed may not erode instantaneously due to cohesive behaviour of the sediment. This uncertainty would cause a shift in the locations where sediment has accumulated. Cohesive sediment behaviour would also increase the critical bed shear stress for erosion. Therefore, it is recommended to characterise the cohesive properties of sediment in the DWDS. 


\section{Conclusions and recommendations}

Detailed hydraulic simulations have been performed with a temporal resolution of $1 \mathrm{~s}$ and with three modelling approaches: an EPANET model (quasi steady state), a Rigid Column model and a waterhammer model. We have investigated whether the more advanced hydraulic modelling approaches provide necessary conditions or unambiguous criteria for the presence of sedimentation in a DWDS. The detailed simulation results have been combined with turbidity measurements during flushing procedures in order to identify promising sedimentation criteria, which are summarised hereafter.

The Rigid Column simulation is practically identical with the EPANET simulation. The water hammer simulation shows velocity oscillations of approximately $2 \mathrm{~cm} \mathrm{~s}^{-1}$ and $2 \mathrm{~cm} \mathrm{~s}^{-2}$ around the EPANET solution, independent of the magnitude of the velocity. It is recommended to verify these transient velocities with flow measurements with sufficient temporal resolution. The more detailed simulations do not lead to different flow distributions in the Purmerend DWDS.

The presence of stagnation zones and multiple flow direction reversals may serve as alternative parameters to predict sediment accumulation, which are consistent with theoretical considerations on critical shear stresses and with the observed turbidity data. The analysis of critical shear stress, including unsteady shear stresses, confirms that sediment in the DWDS must exhibit cohesive behaviour to accumulate any material. It is recommended to determine the cohesive properties of sediment in DWDS. A direct consequence of the analysis in this paper states that sediment accumulation will not occur in branched distribution networks, because of the low critical shear stress for resuspension and low terminal velocity of typical particles. It suggests that branched distribution networks will be self-cleaning if the daily maximum velocity exceeds $0.06 \mathrm{~m} \mathrm{~s}^{-1}$ (Fig. 3), assuming that all particles have a diameter $d<25 \mu \mathrm{m}$ and density $\rho_{\mathrm{s}}<1200 \mathrm{~kg} \mathrm{~m}^{-3}$ and exhibit non-cohesive behaviour.

Acknowledgements. The authors acknowledge PWN Water Supply North Holland for their co-operation and permission to publish the turbidity data.

Edited by: R. Farmani

\section{References}

Blokker, E. J. M.: Stochastic water demand modelling for a better understanding of hydraulics in water distribution networks, Civil Engineering and Geosciences, Ph.D. thesis, 205, 978-90-8957015-4, 2010.

Blokker, E. J. M., Vreeburg, J. H. G., Schaap, P. G., and van Dijk, J. C.: The self-cleaning velocity in practice, Water Distribution System Analysis, Tucson, AZ, 12-15 September, 2010a.

Blokker, E. J. M., Vreeburg, J. H. G., and van Dijk, J. C.: Simulating residential water demand with a stochastic end-use model, J. Water Res. Pl.-ASCE, 136, 19-26, 2010 b.

Blokker, E. J. M., Schaap, P. G., and Vreeburg, J. H. G.: Comparing the fouling rate of one drinking water distribution systems in two different flow configurations, Computing and Control in the Water Industry (CCWI), Exeter, September, 2011.

Brunone, B., Karney, B. W., Mercarelli, M., and Ferrante, M.: Velocity profiles and unsteady pipe friction in transient flow, J. Water Res. Pl.-ASCE, 126, 236-244, 2000.

Deltares: WANDA, pipeline simulation software, Deltares Software, 1993-2011.

Ebacher, G., Besner, M. C., Lavoie, J., Jung, B. S., Karney, B. W., and Prévost, M.: Transient Modeling of a Full-Scale Distribution System: Comparison with Field Data, J. Water Res. Pl.-ASCE, 137, 173-182, 2011.

Pothof, I. W. M.: A turbulent approach to unsteady friction, J. Hydraul. Res., 46, 679-690, 2008.

Rossman, L. A.: EPAnet 2 User Manual, 2000.

Schaap, P. G. and Blokker, E. J. M.: Carefully designed measurements provide insight into sediment build-up in drinking water distribution systems, Computing and Control in the Water Industry (CCWI), Exeter, UK, September, 2011.

Soulsby, R. L.: Dynamics of marine sand, Thomas Telford, 1997.

Vardy, A. E. and Brown, J. M. B.: Transient turbulent friction in smooth pipe flows, J. Sound Vib., 259, 1011-1036, 2003.

Vreeburg, J. H. G.: Discolouration in drinking water systems: a particular approach, PhD, Civil Engineering and Geosciences, Delft University of Technology, Delft, 183 pp., 2007.

Wylie, E. B. and Streeter, V. L.: Fluid Transients in Systems, Prentice-Hall, New York, 1993.

Zielke, W.: Frequency dependent friction in transient pipe flow, ASME J. Basic Engineering, 90, 109-115, 1968. 